\title{
Monetary Policy and Financial Markets at the Effective Lower Bound*
}

\author{
Lars E.O. Svensson, \\ Sveriges Riksbank, Stockholm University, CEPR, and NBER
}

First version: June 2009

This version: June 2010

\begin{abstract}
I discuss what determines the effective lower bound (ELB) for the policy rate and argue that the ELB is not hard, but rather soft, and that it is probably slightly negative. I argue that, at the ELB, current output can be increased by (1) monetary policy that extends the period of credibly low policy rates and generates inflation expectations, (2) financial-stability policy - which is distinct from monetary policy - that reduces the spreads between market interest rates and the policy rate, and (3) fiscal policy that increases the neutral real rate by reducing expected growth of government expenditure and increases potential output by increasing current government expenditure.
\end{abstract}

JEL Classification: E52, E58, E43

Keywords: Zero lower bound

\section{Introduction}

The financial crisis is abating. During the financial crisis, spreads in financial markets rose dramatically but they have, at the time of writing (April 2010), come down to much lower levels (figure 1.1). Central banks responded to the crisis by lowering policy rates dramatically. Policy rates are now expected to stay low for some time and then rise slowly or faster depending on the country (figure 1.2). ${ }^{1}$ The low policy rates raise the question, how low is the effective lower bound for policy rates?

${ }^{*}$ This a revised and updated version of a speech held on June 4, 2009, at the conference "Financial Markets and Monetary Policy," Federal Reserve Board. The views expressed here are my own and are not necessarily shared by other members of the Riksbank's Executive Board or staff. I thank thank Meredith Beechey for comments. Carl-Andreas Claussen, Megan Owens, and Per Åsberg-Sommar have contributed to this speech.

${ }^{1}$ Market expectations in figure 1.2 are smoothed curves based on overnight index swaps, forward rate agreements, futures contracts and interest-rate swaps (depending on the country). They have been adjusted by the Riksbank staff for possible risk premia so as to be the staff's best estimate of market expectations of future policy rates. The uncertainty about term premia and expected long-run interbank-OIS spreads are deemed by the staff to be larger for Canada and Japan. 
Figure 1.1: Spreads between 3-month interbank and OIS rates (percentage points)

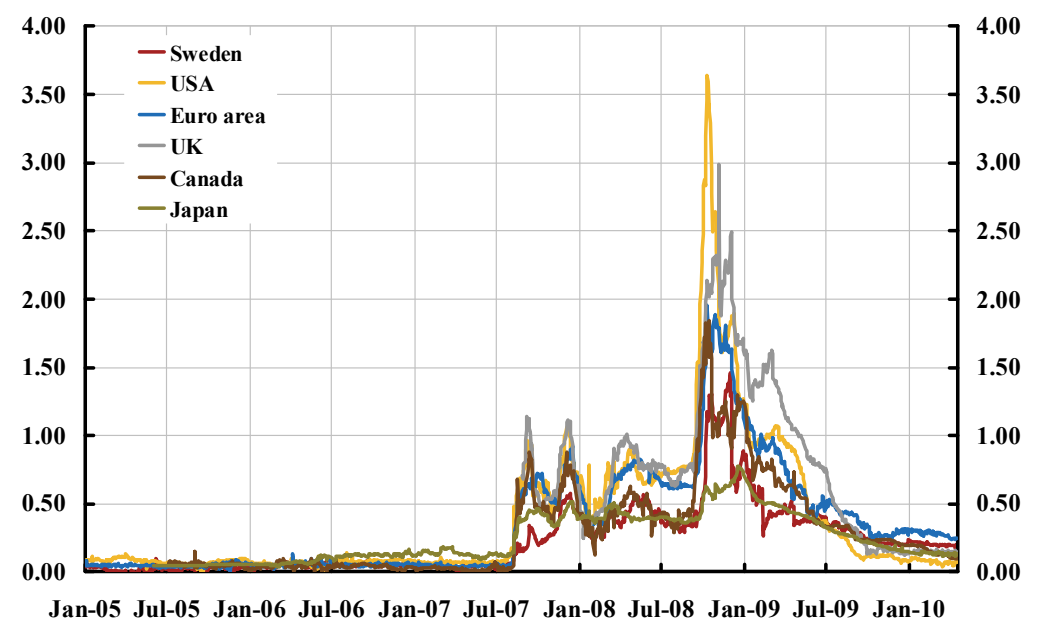

\section{How low is the effective lower bound for policy rates?}

So how low is the effective lower bound (ELB) for policy rates? Is it positive, zero, or even negative? The Bank of England has not lowered its policy rate below 0.5 percent, citing that pass-through on to other rates may be limited (Bank of England (2009, Box p. 44-45)). But this might be an argument for even lower policy rates. It was also suggested that there might be adverse effects on some financial markets and on some banks' margins between lending and deposit rates.

At the Riksbank, the majority of the Executive Board has decided since July 2009 not to lower the repo rate below 0.25 percent. I have dissented in favor of a repo rate of zero percent. ${ }^{2}$ I do not see any problems in going to a zero policy rate. I am not convinced by the arguments that such a low policy rate will imply any severe problems for financial markets or threaten financial stability. Any adverse effect on financial markets and financial stability should be balanced against the stimulative effects on the real economy of a further reduction of the policy rate. Other central banks have gone to very low policy rates without apparent problems. Japan has had a policy rate of 0.1 percent for a long time, Switzerland has had a repo rate of 0.02 percent, the U.S. has an interval between 0 and 0.25 percent for the federal funds rate, and Canada has a policy rate of 0.25 percent. I am not aware of the low policy rates having caused any major problems for financial markets in those countries. Sweden now (April 2010) has a policy rate of 0.25 percent and has had so since

\footnotetext{
${ }^{2}$ The Riksbank is unique in publishing detailed attributed minutes (in Swedish and English) of each policy meeting. They are available about two weeks after each meeting on the Riksbank's website, www.riksbank.com. There, anyone interested can follow the detailed discussion and arguments between my colleagues and me.
} 
Figure 1.2: Policy rates and market expectations (percent)

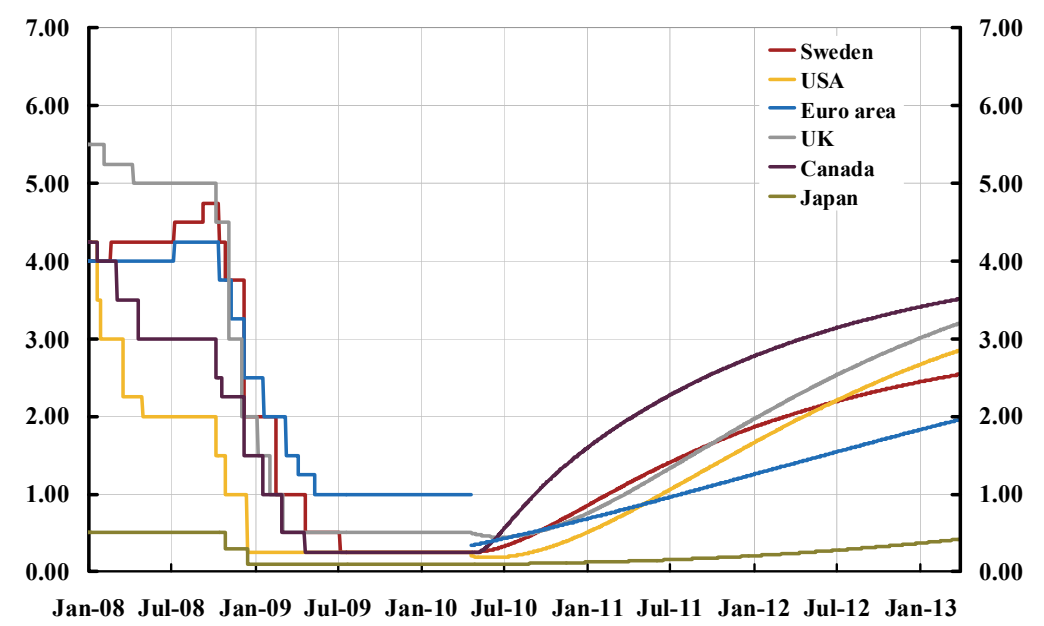

July 2009. No problems were found by Beechey and Elmér (2009) in September 2009. Since then a few more months have passed. Both the Monetary Policy Department and the Financial Stability Department at the Riksbank closely follow developments in the financial markets and have very good information about them. There are still no signs as of April 2010 that low interest rates have led to any problems with regard to financial stability or the functioning of the financial markets. The profitability of the major banks, in the form of net interest margin, has been stable and their share of deposits from households has not changed noticeably. The redistribution of capital on the fund market has also been moderate. The financial infrastructure has not been affected by any problems during the period of low interest rates and resilience against disruptions of the financial infrastructure is deemed to be high.

Generally, I believe one should be aware of an unwarranted zero mystique around nominal interest rates. It should not be forgotten that nominal interest rates are just a convention for expressing intertemporal relative prices. Given this perspective, there is nothing special about negative nominal interest rates. Consider a 12-month Treasury bill with a nominal value of a 100 million dollars. A nominal interest rate of plus 1 percent, 0 percent, and minus 1 percent corresponds to a present value of this Treasury bill of (approximately) 99, 100 or 101 million dollars, respectively. Why would the market's ability to trade this asset differ depending on these alternative prices and interest rates? Furthermore, for economic decisions it is mostly real interest rates that matter, not nominal ones, and real interest rates are often negative.

In particular, imagine a cashless economy. There are no paper notes, and money can only be 
held in accounts. With the increased use of bank cards and credit cards even for small transactions, for instance with the use of payment terminals for PINs that are increasingly common, this does not seem particularly unrealistic. In such a cashless economy, we would have an equilibrium nominal interest-rate structure, with more liquid and safe assets/accounts having lower rates and less liquid and safe assets/accounts having higher rates. The whole interest-rate structure would shift up and down depending on what the equilibrium benchmark nominal interest rate is. But there would be nothing special about it being zero. Interest rates could be positive, zero, or negative. (Negative interest rates could be called fees.) For investors choosing between investments with varying degrees of liquidity and safeness, only the relative interest rates would matter.

Now consider the existence of cash in the form of paper notes, currency. Currency pays a zero interest rate. The argument against negative nominal rates is usually that depositors and investors would prefer to withdraw their deposits and instead hold cash in the form of currency rather than pay negative interest rates. But holding currency in large amounts implies costs. There are storage costs, including crime prevention. There are also payment inconveniences. At least in Sweden, large payments cannot be made with cash. Instead payments are made by transfers between bank accounts. In that sense, paradoxically, large amounts of cash are not very liquid. You first have to deposit them into an account before they become liquid.

Thus, if we take into account these holding and handling costs of cash, cash effectively pays a negative interest rate, not zero. Then, the crucial question is, at what (negative) interest-rate level would depositors start to withdraw large amounts from their accounts and instead hold sizeable amounts of cash? For one thing, this would not go unnoticed. Banks would obviously immediately notice that large withdrawals are being made. The withdrawals would quickly show up in increased demand for currency and show up on the liability side of central banks' balance sheets under the item "Currency in circulation." (Of course, a bank that sets a negative deposit rate (a deposit fee) and sees its deposits shrink quickly would have second thoughts and raise the deposit rate to keep the required level of deposits, or shift to market funding if possible.)

How sensitive deposits are to negative rates would vary a lot between different kinds of depositors. Some would withdraw their money in anger and rather suffer the inconveniences of handling large amounts of cash in the form of currency. Others would make rational calculations of the benefits and costs and probably keep their deposits, even at moderately negative rates. As a consequence, the effective lower bound is not hard, but rather soft, and it is most likely not zero, but somewhat negative. The effective lower bound would also depend, of course, on the length of the 
period the interest rate is expected to be kept so low.

How could one find out where the effective lower bound is? One possibility is to lower the policy rate to zero and then below and to see what happens. If large deposit withdrawals start to occur, the policy rate could be moved back up. I do not view there to be any substantial economic costs with such experimentation, and in any case any costs should be balanced against the benefits of stimulating the economy.

\section{Monetary policy with a binding ELB}

How should we look at monetary policy when the policy rate is at the effective lower bound? Let me use the simplest possible New Keynesian model to illustrate.

The loglinearized Euler condition for optimal intertemporal consumption choice by the private sector will be

$$
c_{t}=c_{t+1 \mid t}-\sigma\left(r_{t}-\rho_{t}\right) .
$$

Here $c_{t}$ denotes (the log of) consumption in period $t ; c_{t+1 \mid t} \equiv \mathrm{E}_{t} c_{t+1}$ denotes private-sector expectations in period $t$ of consumption in period $t+1 ; \sigma>0$ denotes the intertemporal elasticity of substitution; $r_{t} \equiv i_{t}-\pi_{t+1 \mid t}$ denotes the real market interest rate, where $i_{t}$ is the nominal market interest rate, $\pi_{t+1 \mid t} \equiv p_{t+1 \mid t}-p_{t}$ denotes private-sector expectations in period $t$ of inflation $\pi_{t+1} \equiv p_{t+1}-p_{t}$ in period $t+1$, and $p_{t}$ denotes the $(\log )$ price level in period $t$; and $\rho_{t}$ denotes the rate of time preference in period $t$ between consumption in period $t$ and $t+1$. Output is the sum of consumption and government expenditure (there is no investment), which in loglinearized form gives

$$
y_{t}=\alpha c_{t}+(1-\alpha) g_{t}
$$

where $y_{t}$ denotes $(\log )$ output in period $t, \alpha \equiv C / Y(0<\alpha<1)$ denotes the steady-state share of consumption in output, and $g_{t}$ denotes $(\log )$ government expenditure. Eliminating $c_{t}$ and $c_{t+1 \mid t}$ in (3.1) and (3.2) gives an equation for aggregate demand,

$$
\frac{1}{\alpha} y_{t}-\frac{1-\alpha}{\alpha} g_{t}=\frac{1}{\alpha} y_{t+1 \mid t}-\frac{1-\alpha}{\alpha} g_{t+1 \mid t}-\sigma\left(r_{t}-\rho_{t}\right) .
$$

Potential (flexprice) output $\bar{y}_{t}$ and the neutral (real) (market) interest rate $\bar{r}_{t}$ will then satisfy

$$
\frac{1}{\alpha} \bar{y}_{t}-\frac{1-\alpha}{\alpha} g_{t} \equiv \frac{1}{\alpha} \bar{y}_{t+1 \mid t}-\frac{1-\alpha}{\alpha} g_{t+1 \mid t}-\sigma\left(\bar{r}_{t}-\rho_{t}\right) .
$$

Solving for the neutral interest rate gives

$$
\bar{r}_{t} \equiv \rho_{t}+\frac{1}{\sigma \alpha}\left(\bar{y}_{t+1 \mid t}-\bar{y}_{t}\right)-\frac{1-\alpha}{\sigma \alpha}\left(g_{t+1 \mid t}-g_{t}\right),
$$


where $\bar{y}_{t+1 \mid t}-\bar{y}_{t}$ is expected potential-output growth and $g_{t+1 \mid t}-g_{t}$ is expected governmentconsumption growth.

Assume that the private sector has an additively separable utility function, $u\left(C_{t}\right)-v\left(H_{t}\right)$, where the increasing and concave function $u\left(C_{t}\right)$ denotes the utility from consumption, $C_{t}$, and the increasing and convex function $v\left(H_{t}\right)$ denotes disutility from hours worked, $H_{t}$. For simplicity, disregard any utility from government consumption; alternatively assume that it enters additively separably. Then potential output, $\bar{Y}_{t}$, and potential hours, $\bar{H}_{t}$, are related by

$$
u^{\prime}\left(\bar{Y}_{t}-G_{t}\right)=\frac{v^{\prime}\left(\bar{H}_{t}\right)}{\bar{W}_{t} / \bar{P}_{t}}
$$

where a prime denotes the derivative and $\bar{W}_{t} / \bar{P}_{t}$ denotes potential real wages. (For simplicity, nondistortionary lump-sum taxes are available to finance government consumption.) Assume that output depends on hours worked according to the increasing and concave production function, $Y_{t}=f\left(H_{t}\right)$. Then potential real wages and potential hours satisfy

$$
\bar{W}_{t} / \bar{P}_{t}=f^{\prime}\left(\bar{H}_{t}\right)
$$

Thus, potential output and government expenditure satisfy

$$
u^{\prime}\left(\bar{Y}_{t}-G_{t}\right)=\frac{v^{\prime}\left(\bar{H}_{t}\right)}{\bar{W}_{t} / \bar{P}_{t}}=\frac{v^{\prime}\left(\bar{H}_{t}\right)}{f^{\prime}\left(\bar{H}_{t}\right)}=\frac{v^{\prime}\left(f^{-1}\left(\bar{Y}_{t}\right)\right)}{f^{\prime}\left(f^{-1}\left(\bar{Y}_{t}\right)\right)} \equiv \tilde{v}^{\prime}\left(\bar{Y}_{t}\right),
$$

where $\tilde{v}^{\prime}\left(Y_{t}\right)$ is the marginal disutility of producing output (which will be increasing on output, so $\left.\tilde{v}^{\prime \prime}>0\right)$. It follows that potential output depends on government expenditure according to

$$
\begin{aligned}
\frac{d \bar{Y}_{t}}{d G_{t}} & =\frac{\tilde{v}^{\prime \prime}}{\tilde{v}^{\prime \prime}-u^{\prime \prime}} \equiv m<1, \\
\frac{e \bar{Y}_{t}}{e G_{t}} & =\frac{\bar{y}_{t}}{g_{t}}=\frac{d \bar{Y}_{t}}{d G_{t}} \frac{G}{Y}=m(1-\alpha)<1,
\end{aligned}
$$

where $e \bar{Y}_{t} / e G_{t}$ denotes the elasticity of potential output with respect to government expenditure. Thus, (log) potential output is increasing in (log) government expenditure,

$$
\bar{y}_{t}=m(1-\alpha) g_{t}
$$

It also follows that expected potential-output growth depends on expected government expenditure growth according to $\bar{y}_{t+1 \mid t}-\bar{y}_{t}=m(1-\alpha)\left(g_{t+1 \mid t}-g_{t}\right)$, which together with (3.5) gives the following expressing for the neutral interest rate:

$$
\bar{r}_{t}=\rho_{t}+\frac{1-\alpha}{\sigma \alpha}(m-1)\left(g_{t+1 \mid t}-g_{t}\right)
$$


Thus, the neutral rate is increasing in the rate of time preference and decreasing in the expected growth of government expenditure.

It follows from (3.3) and (3.4) that the output gap, $y_{t}-\bar{y}_{t}$, satisfies

$$
\begin{aligned}
y_{t}-\bar{y}_{t} & =y_{t+1 \mid t}-\bar{y}_{t+1 \mid t}-\sigma \alpha\left(r_{t}-\bar{r}_{t}\right) \\
& =\underbrace{y_{t+T \mid t}-\bar{y}_{t+T \mid t}}_{\approx 0}-\sigma \alpha \sum_{\tau=0}^{T-1}\left(r_{t+\tau \mid t}-\bar{r}_{t+\tau \mid t}\right),
\end{aligned}
$$

where in the second line I have solved the output gap forward to period $t+T$ and assumed that $T$ is sufficiently large that the expected output gap is approximately zero. Then output is given by the approximation

$$
y_{t} \approx \bar{y}_{t}-\sigma \alpha \sum_{\tau=0}^{T-1}\left(r_{t+\tau \mid t}-\bar{r}_{t+\tau \mid t}\right)=m(1-\alpha) g_{t}-\sigma \alpha \sum_{\tau=0}^{T-1}\left(r_{t+\tau \mid t}-\bar{r}_{t+\tau \mid t}\right),
$$

where I have used (3.6). We see that output in period $t$ depends positively on potential output in period $t$ and negatively on the sum of expected future (market) interest-rate gaps, $\sum_{\tau=0}^{T-1}\left(r_{t+\tau \mid t}-\right.$ $\left.\bar{r}_{t+\tau \mid t}\right)$.

Let us now write the market nominal interest rate, $i_{t}$, as the sum of the policy rate, $i_{t}^{p}$, and the spread, $\delta_{t}$, between the market nominal rate and the policy rate,

$$
i_{t}=i_{t}^{p}+\delta_{t}
$$

Then the market real interest rate can be written $r_{t} \equiv i_{t}-\pi_{t+1 \mid t}=i_{t}^{p}+\delta_{t}-\pi_{t+1 \mid t}$. Using this in the sum of the expected future interest-rate gaps, we have

$$
\sum_{\tau=0}^{T-1}\left(r_{t+\tau \mid t}-\bar{r}_{t+\tau \mid t}\right)=\sum_{\tau=0}^{T-1} i_{t+\tau \mid t}^{p}+\sum_{\tau=0}^{T-1} \delta_{t+\tau \mid t}-\left(p_{t+T \mid t}-p_{t}\right)-\sum_{\tau=0}^{T-1} \bar{r}_{t+\tau \mid t} .
$$

Let us now assume that there is an ELB, $\bar{\imath} \leq 0$, such that the policy rate must satisfy $i_{t}^{p} \geq \bar{\imath}$. Furthermore, assume that, for reasons that are not modelled but could for instance include expected low productivity growth, the neutral interest rate is very low, so that with a binding ELB output is low and the output gap is negative. How can policy contribute to increasing output?

In (3.8) we see that output in period $t$ is negatively related to the accumulated market interestrate gap, and in (3.9) we see that the accumulated interest-rate gap consists of four terms. Let us look at these in turn.

The first term in (3.9) is the sum of expected policy rates, $\sum_{\tau=0}^{T-1} i_{t+\tau \mid t}^{p}$. By inducing expectations of lower future policy rates, for instance by credible announcements of an extended period of low policy rates, the central bank can this way contribute to increased output. 
The second term in (3.9) is the sum of expected spreads between market and policy rates, $\sum_{\tau=0}^{T-1} \delta_{t+\tau \mid t}$. By introducing financial-stability policy policy - such as liquidity policy, credit easing, and so forth - that improves the functioning of the interbank market, the central bank and other authorities responsible for financial-stability policy may induce lower spreads, and this way contribute to increased output. (The distinction between financial-stability policy and monetary policy is further discussed below.)

The third term in (3.9) is expected accumulated inflation, $\sum_{\tau=1}^{T-1} \pi_{t+\tau \mid t}=p_{t+T \mid t}-p_{t}$, the expected growth of the price level between period $t$ and period $t+T$. By inducing increased inflation expectations over this period, the central bank can contribute to increased output.

The fourth term in (3.9) is the sum of expected future neutral rates, $\sum_{\tau=0}^{T-1} \bar{r}_{t+\tau \mid t}$. By (3.7), this term is given by

$$
\sum_{\tau=0}^{T-1} \bar{r}_{t+\tau \mid t}=\sum_{\tau=0}^{T-1} \rho_{t+\tau \mid t}+\frac{1-\alpha}{\sigma \alpha}(m-1)\left(g_{t+T \mid t}-g_{t}\right) .
$$

Thus, fiscal policy that induces expectations of lower expected government expenditure growth between period $t$ and period $t+T$ will lower the sum of neutral policy rates and contribute to higher output. One way to do this with a balanced budget over time is to increase current expenditure, $g_{t}$, and lower expected future expenditure, $g_{t+T \mid t}$. This points to the importance of a credible and sustainable fiscal policy.

Furthermore, we see in (3.6) and (3.8) that increased current government expenditure increases potential output and thereby current output.

In sum, with a binding ELB, current output can be increased by monetary policy, financialstability policy, and fiscal policy. Monetary policy can contribute by extending the period of expected low policy rates and by generating inflation expectations. Financial-stability policy can contribute by reducing the spreads between market interest rates and the policy rate. Fiscal policy, finally, can contribute by increasing current government expenditure, which has a direct effect on potential and actual output, and by reducing expected growth of government expenditure, which has an indirect effect on output through an increase of the sum of expected future neutral rates. Let me now look more closely at each of these ways to increase output.

\subsection{Keep expectations of future policy rates down}

Announcing a low future policy rate has been called "forward guidance" and has been practiced by, for instance, the Federal Reserve, the Bank of Canada, and the Riksbank, the former two with 
Figure 3.1: Repo rate and market expectations, February 2009

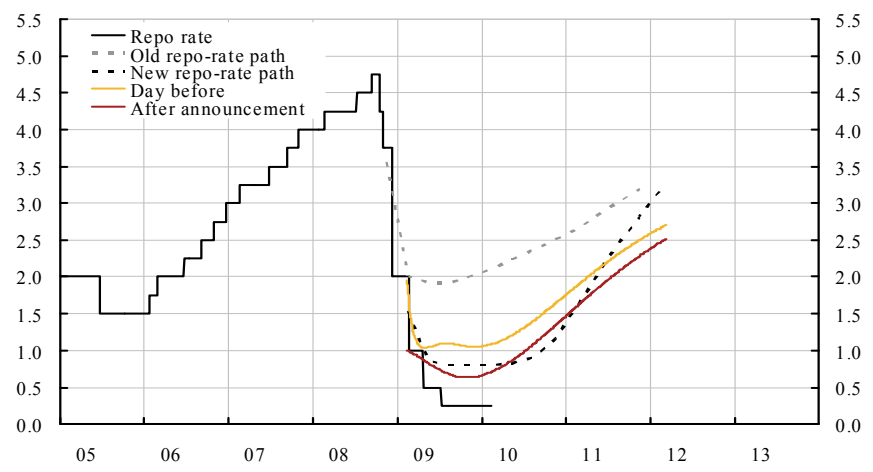

verbal announcements, the latter with its published policy-rate path. Announcing a low future policy rate aims at affecting policy-rate expectations. Hence, the credibility of the announcement is crucial. The Riksbank's experience of managing expectations provides an interesting example.

In Svensson (2009) I concluded that the Riksbank's management of policy-rate expectations had been overall pretty successful from the introduction of a published policy-rate in February 2007 up to and including the policy meeting of December 2008. As I discuss in some more detail in Svensson (2010b), the experience during 2009 has been somewhat different. Figure 3.1 shows the situation at the policy announcement on February 11, 2009. The solid step-shaped black line shows the actual repo rate. The gray dotted curve shows the previous repo-rate path, from the announcement on December 4, 2008. The black dotted curve shows the new repo-rate path announced on February 11, 2009. The repo rate was lowered from 2 percent to 1 percent, and the path was shifted down by slightly more than 100 basis points. The yellow (gray on a black-and-white printer) solid curve shows market expectations of the repo-rate path at the end of the day before the announcement. Even though this was a big shift in the repo-rate path, it was anticipated pretty well by the market. The ability of the market to predict and understand monetary policy and the Riksbank's ability to conduct a predictable policy both seemed good. The red (black on a black-and-white printer) solid curve shows the market expectations after the announcement. The alignment between market expectations and the published path is pretty good, at least for the first two years. We can say that the repo-rate path published in February had good credibility.

Figure 3.2 shows the situation when the new repo-rate path was announced on April 21, 2009. The repo rate was lowered by 50 basis points to a new level of 50 basis points. The repo-rate path was shifted down by about 50 basis points and remained flat at 50 basis points through 
Figure 3.2: Repo rate and market expectations, April 2009

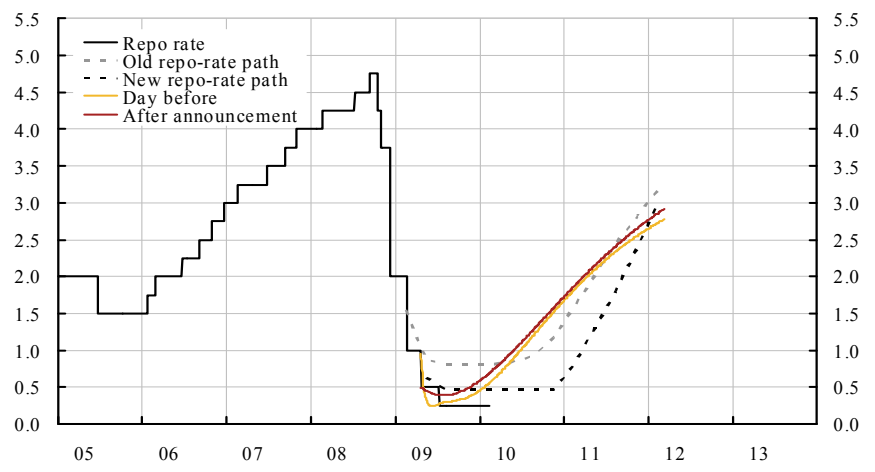

2010. The yellow (gray) curve shows that the market expected the repo rate to be lowered to 25 basis point and that expectations after the announcement shifted up a bit. Importantly, both before and after the announcement, the market expected a substantially higher repo rate during 2010 than the announced repo-rate path. Hence, April 2009 represents a major exception to the Riksbank's previous mostly successful management of expectations. For several months the market then consistently expected a repo-rate path that after a few quarters was significantly above the published repo-rate path. In July 2009, the Riksbank lowered the repo rate to 25 basis points and the repo-rate path was shifted down by about 25 basis points. The Riksbank also announced that, at 25 basis points, the repo rate had probably reached its effective lower bound. After the announcement, market expectations shifted down and agreed with the announced path through 2009 but, similar to after the April announcement, the market expected repo rates in 2010 to be much higher than the published path.

The Riksbank kept the repo-rate path unchanged through the fall until December 2009, during which period market expectations moved closer to the repo-rate path for 2010. However, at the time the market expectations were quite a bit lower than the repo-rate path for 2011, as shown in figure 3.3. Clearly, the Riksbank has had some difficulties making its repo-rate path credible during this period. Possible reasons include communication problems and challenges that are discussed in some detail in Svensson (2010b). For instance, the Riksbank has stated that its forecasts, including the repo-rate path, are mean forecasts. It regularly repeats the mantra "the repo-rate path is a forecast not a promise" and that future repo rates may be both above and below the repo-rate path. However, the majority's announcement in July 2009 about 25 basis points being the effective lower bound may seem inconsistent with the repo-rate path being a mean forecast. It could be interpreted 
Figure 3.3: Repo rate and market expectations, December 2009

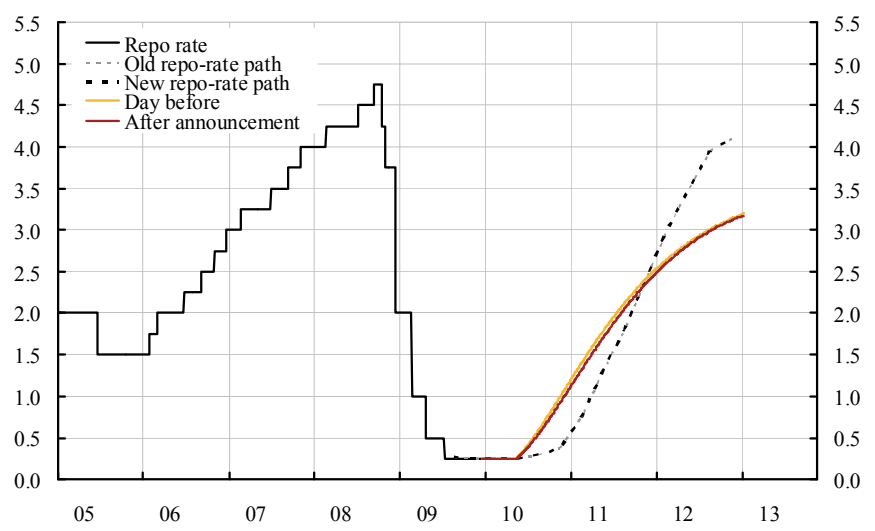

as an unconditional promise not to go below 25 basis points, implying that the probability of a lower repo rate was zero and that all uncertainty was on the up side.

Lending by the central bank at longer maturities at a fixed rate equal to the policy rate may reduce interbank rates of corresponding maturities and also indicate that the central bank takes the repo-rate path as a mean forecast seriously (under which assumption the expected cost for the central bank of this operation would be zero). This might improve the credibility of a repo-rate path with a low policy rate for an extended period. In July, September, and October 2009, the Riksbank did provide 12-month loans (11-month in October) at a fixed rate plus a term premium of 15 basis points. There are some indications that repo-rate expectations fell because of the loans, perhaps in total some 20-30 basis points. The effect on the interbank rate and repo-rate expectations may have been limited by the fact that the volume was limited and that bids exceeded the volume. However, for the October loan, bids fell short of the maximum volume.

\subsection{Keep spreads down}

The spreads between interbank rates and expected policy rates depend on several factors, including credit risk, level of liquidity, and policy-rate uncertainty. Supply of liquidity through variable-rate loans, what can be called liquidity policy or credit easing, aims at improving the functioning of the interbank market and financial markets in general. It is therefore financial-stability policy rather than monetary policy. However, with the policy rate unchanged at the ELB, any financial-stability policy that reduces the spreads has a direct effect on market rates and this way contributes to 
increasing output. ${ }^{3}$

\subsubsection{Monetary policy and financial-stability policy}

As an aside, let me briefly expound on the distinction between monetary policy and financialstability policy, a distinction that is often missed in the current debate. As discussed in more detail in Svensson (2010a) and Svensson (2011, Section 5.2), I believe it is important to conceptually distinguish financial-stability policy from monetary policy. Economic policies can be distinguished by their objectives, instruments, and responsible authority or authorities. Monetary policy is an unusually clear and simple economic policy. In the form of flexible inflation targeting, it has the objective of stabilizing both inflation around the inflation target and resource utilization around a normal level. The suitable instruments are under normal circumstances the policy rate and communication, including possibly a published policy-rate path and a forecast of inflation and the real economy. In times of crisis, as we have seen during the current crisis, other more unconventional instruments can be used, such as fixed-rate lending at longer maturities, asset purchases (quantity easing), and foreign-exchange intervention to prevent currency appreciation. The authority responsible for monetary policy is typically the central bank.

Financial-stability policy is more complex with regard to objectives, instruments, and responsible authorities. It has the relatively complex objective of maintaining or promoting financial stability. A possible definition of financial stability is a situation in which the financial system can fulfil its main functions (of submitting payments, channeling saving into investment, and providing risk sharing) without disturbances that have significant social or economic costs. The available instruments are under normal circumstances supervision, regulation (including macroprudential regulation), and financial-stability reports with analyses and leading indicators that may provide early warnings of stability threats. In times of crisis, there are instruments such as lending of last resort, variable-rate lending at longer maturities (liquidity policy, credit policy, credit easing), special resolution regimes for financial firms in trouble, government lending guarantees, government capital injections, and so forth. The responsible authority or authorities vary across countries. In some countries it is the central bank, in other countries there is a separate financial supervisory authority, sometimes the responsibility is shared between different institutions. In Sweden, the Financial Supervisory Authority is responsible for supervision and regulation, the Riksbank is responsible

\footnotetext{
${ }^{3}$ Part of the spread is a risk premium that depends on policy-rate uncertainty. A commitment to maintain the policy rate at a low level for an extended period should reduce policy-rate uncertainty and contribute to reducing that part of the spread.
} 
for lending of last resort to solvent banks and for promoting a safe and efficient payment system, while the National Debt Office is responsible for bank guarantees and the resolution of failed banks. During times of crisis, these authorities cooperate closely with the Ministry of Finance.

My point here is that financial-stability policy and monetary policy are quite different, with different objectives, instruments, and responsible authorities, the latter with considerable differences across countries. This does not mean that there is no interaction between them. Financial stability directly affects the financial markets, and financial conditions affect the transmission mechanism of monetary policy. Problems in financial markets may have a drastic effect on the real economy, as the current financial crisis has shown. Monetary policy affects asset prices and balance sheets and can thereby affect financial stability. But the fact that financial-stability policy and monetary policy are conceptually distinct, with distinct objectives and distinct suitable instruments, has to be taken into account, for instance, when considering the lessons of the financial crisis for monetary policy. Thus, because the policy rate is a blunt and unsuitable instrument for achieving financial stability, it makes little sense to assign the objective of financial stability to monetary policy, although it may make sense to assign that objective to the central bank, if the central bank controls the appropriate supervisory and regulatory instruments.

\subsection{Keep inflation expectations up}

A credible promise to achieve high inflation in the future, for instance, by keeping a low future policy rate, would imply higher inflation expectations and therefore a lower real interest rate. The crucial issue is whether such a promise can be made credible or not, as discussed in Krugman (1998) and Svensson (2003). A credible positive inflation target helps. But optimal policy may call for inflation above the inflation target. In this case, a credible price-level target (or average inflation targeting) would be useful, as a fall in the price level below the target would imply higher inflation expectations. Quantitative easing, that is, expanding the monetary base through purchases of assets would generate expectations of a higher future price level if it was believed to be permanent. Without a credible commitment to a permanently higher future monetary base, quantitative easing is unlikely to affect expectations of the future price level (see Svensson (2003) for references on and discussion of this issue). 


\subsection{Keep the neutral real rate up}

As seen in (3.10), fiscal policy in the form of an increase in current government expenditure and/or a credible future reduction in government expenditure will, everything else equal, increase the sum of expected future neutral real interest rate and in this way, everything else equal, reduce the accumulated interest-rate gap and contribute to a higher output. In a more sophisticated analysis of the effect of financial frictions, the neutral rate may itself depend on financial frictions (see, for instance, Curdia and Woodford (2009)). An increase in current government expenditure also has a direct positive effect on potential output and actual output.

\section{Summary}

I have discussed what determines the effective lower bound (ELB) for the policy rate, that is, the policy rate at which depositors start to withdraw their deposits and instead hold large amounts of cash. I have argued that the ELB is not hard, but rather soft, and that it is probably slightly negative. I have also discussed policy at the ELB with the help of a simple New Keynesian model. Current output can be increased by contributions from monetary policy, financial-stability policy, and fiscal policy. Monetary policy can contribute by extending the period of credibly low policy rates. In that context I have discussed some problems for the Riksbank in making its low repo-rate path credible. Monetary policy can also contribute by generating inflation expectations. Financialstability policy can contribute by reducing the spreads between market interest rates and the policy rate. Fiscal policy can contribute by increasing current government expenditure, which has a direct

effect on potential and actual output, and by reducing expected growth of government expenditure, which has an indirect effect on output through an increase of the sum of expected future neutral rates.

\section{References}

Bank of England (2009), Inflation Report, February 2009, www.bankofengland.co.uk.

Beechey, Meredith, and Heidi Elmér (2009), "The Lower Limit of the Riksbank's Repo Rate," Sveriges Riksbank Economic Commentaries 11, 2009, 1-8, www.riksbank.com.

Curdia, Vasco, and Michael Woodford (2009), "Credit Frictions and Optimal Monetary Policy," BIS Working Paper 278. 
Krugman, Paul R. (1998), "It's Baaack: Japan's Slump and the Return of the Liquidity Trap," Brookings Papers on Economic Activity 2:1998, 137-205.

Svensson, Lars E.O. (2003), "Escaping from a Liquidity Trap and Deflation: The Foolproof Way and Others," Journal of Economic Perspectives 17(4), 145-166.

Svensson, Lars E.O. (2009), "Transparency under Flexible Inflation Targeting: Experiences and Challenges," Sveriges Riksbank Economic Review 1/2009(1), 5-44.

Svensson, Lars E.O. (2010a), "Inflation Targeting after the Financial Crisis," Speech in Mumbai, February 12, 2010, www.riksbank.se.

Svensson, Lars E.O. (2010b), "Policy Expectations and Policy Evaluations: The Role of Transparency and Communication," Sveriges Riksbank Economic Review 1/2010, 43-78.

Svensson, Lars E.O. (2011), "Inflation Targeting," in Friedman, Benjamin M., and Michael Woodford (eds.), Handbook of Monetary Economics, Volume 3b, chap. 22, Elsevier, 1237-1302. 